\title{
Maternal embryonic leucine zipper kinase serves as a poor prognosis marker and therapeutic target in gastric cancer
}

\author{
Shen Li ${ }^{1,2}$, Ziyu Li ${ }^{2}$, Ting Guo ${ }^{1}$, Xiao-Fang Xing ${ }^{1}$, Xiaojing Cheng ${ }^{1}$, Hong Du ${ }^{1}$, Xian-Zi \\ Wen $^{1}$, Jia-Fu Ji $\mathbf{i}^{1,2}$ \\ ${ }^{1}$ Key Laboratory of Carcinogenesis and Translational Research (Ministry of Education), Division of Gastrointestinal Cancer \\ Translational Research Laboratory, Peking University Cancer Hospital \& Institute, Beijing, China \\ ${ }^{2}$ Department of Gastrointestinal Surgery, Peking University Cancer Hospital \& Institute, Beijing, China \\ Correspondence to: Xian-Zi Wen, e-mail: wenxz@bjmu.edu.cn \\ Jia-Fu Ji, e-mail: jiafuj@hotmail.com
}

Keywords: MELK, gastric cancer, prognosis, metastasis, PDX

Received: July 02, 2015

Accepted: December 07, 2015

Published: December 19, 2015

\section{ABSTRACT}

Maternal embryonic leucine zipper kinase (MELK) is upregulated in a variety of human tumors, and is considered an attractive molecular target for cancer treatment. We characterized the expression of MELK in gastric cancer (GC) and measured the effects of reducing MELK mRNA levels and protein activity on GC growth. MELK was frequently overexpressed in primary GCs, and higher MELK levels correlated with worse clinical outcomes. Reducing MELK expression or inhibiting kinase activity resulted in growth inhibition, G2/M arrest, apoptosis and suppression of invasive capability of GC cells in vitro and in vivo. MELK knockdown led to alteration of epithelial mesenchymal transition (EMT)-associated proteins. Furthermore, targeting treatment with OTSSP167 in GC patient-derived xenograft (PDX) models had anticancer effects. Thus, MELK promotes cell growth and invasiveness by inhibiting apoptosis and promoting G2/M transition and EMT in GC. These results suggest that MELK may be a promising target for GC treatment.

\section{INTRODUCTION}

Gastric cancer is the fourth most common malignant tumor and the second leading cause of cancer-related deaths [1]. Despite improvements in detection and management, the 5-year survival rate for GC remains low [2]. Because patients in the early stages of GC are either asymptomatic or report only nonspecific symptoms, by the time of diagnosis the tumor has often progressed to an advanced stage or has even metastasized to distant organs. Metastasis is the most common cause of death in patients with GC [3]. Further study of the molecular mechanisms of $\mathrm{GC}$ development and progression may help identify new molecular targets for more effective therapies.

Molecules that are uniquely overexpressed in cancer cells are ideal targets for the development of anticancer drugs, and treatments focusing on specific molecular targets often have fewer negative side effects. Protein kinases have emerged as the most important targets for drug discovery because of their critical roles in regulating cell growth and survival. Data collected previously using an Affimetrix HG-133 array showed a 3.84-fold increase in $M E L K$ expression in $79 \mathrm{GC}$ tissues as compared to 24 non-cancerous tissues, making it one of the most upregulated genes in GC $(p<0.05)$ (unpublished data).

Maternal embryonic leucine zipper kinase (MELK), also known as murine protein K38 (MPK38) and Eg3 protein, was firstly identified in unfertilized eggs and is now known to be a member of the AMP-activated Ser/Thr protein kinase family [4-6]. During later stages of embryogenesis, $M E L K$ expression is restricted to areas where mesenchymalepithelial interactions are taking place [7]. In normal adult tissues, MELK is expressed only in the testis and at very low levels in the thymus and small intestine [4, 8]. MELK participates in multiple cellular processes, including cell cycle progression, cell proliferation, apoptosis, RNA processing, and cell migration [8-13].

Overexpression of MELK has been detected in a variety of human tumors, including breast cancer, glioblastoma, prostate cancer, colorectal cancer, and acute myeloid leukemia [8, 14-17]. Furthermore, high levels of MELK expression correlate with poor prognoses in patients 
with breast cancer and glioma [18, 19]. Recent research has explored the role of MELK in cancer stem cell maintenance and survival [14, 20, 21]. However, little is known about the relevance of this kinase in gastric malignancies. In this study, we characterized the expression of MELK in GC patients and investigated its role in $\mathrm{GC}$ pathogenesis. We quantified MELK expression in both human GC cell lines and primary GC tissues, and examined the relationships between MELK expression and metastasis, depth of invasion, and poor prognosis in GC patients. MELK mRNA and protein activity were reduced using shRNA and OTSSP167, a small molecule inhibitor of MELK kinase activity [22], and the effects on GC cell growth, G2/M arrest, apoptosis, invasive capability of GC cells, and as well as decreased metastatic colonization in xenograft models were measured.

\section{RESULTS}

\section{Expression of MELK in human GC cell lines and primary GCs}

We assessed the levels of MELK mRNA and MELK protein by polymerase chain reaction (PCR) and Western blotting, respectively, in 8 human GC cell lines. As shown in Fig. S1 and 1A, MELK mRNA was highly expressed in all cell lines and protein levels correlated well with mRNA levels. MELK protein levels were also analyzed in frozen GC specimens and corresponding distal surgical margin tissue from 8 patients using Western blotting (Fig. 1B). MELK was detected in all of the tumor tissues but not in
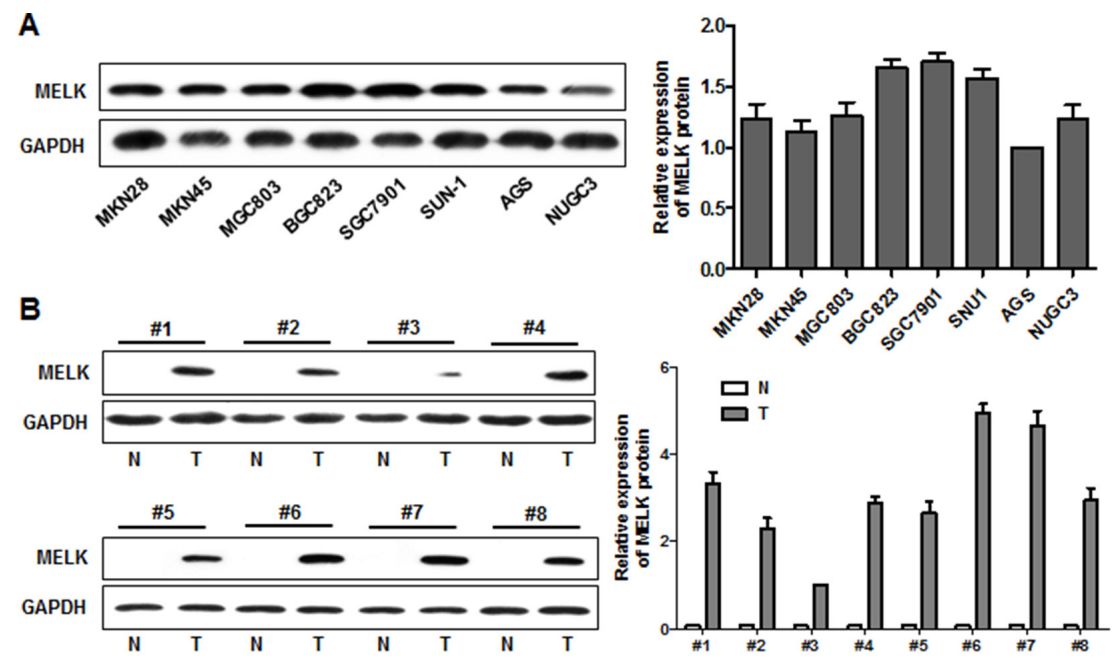

C
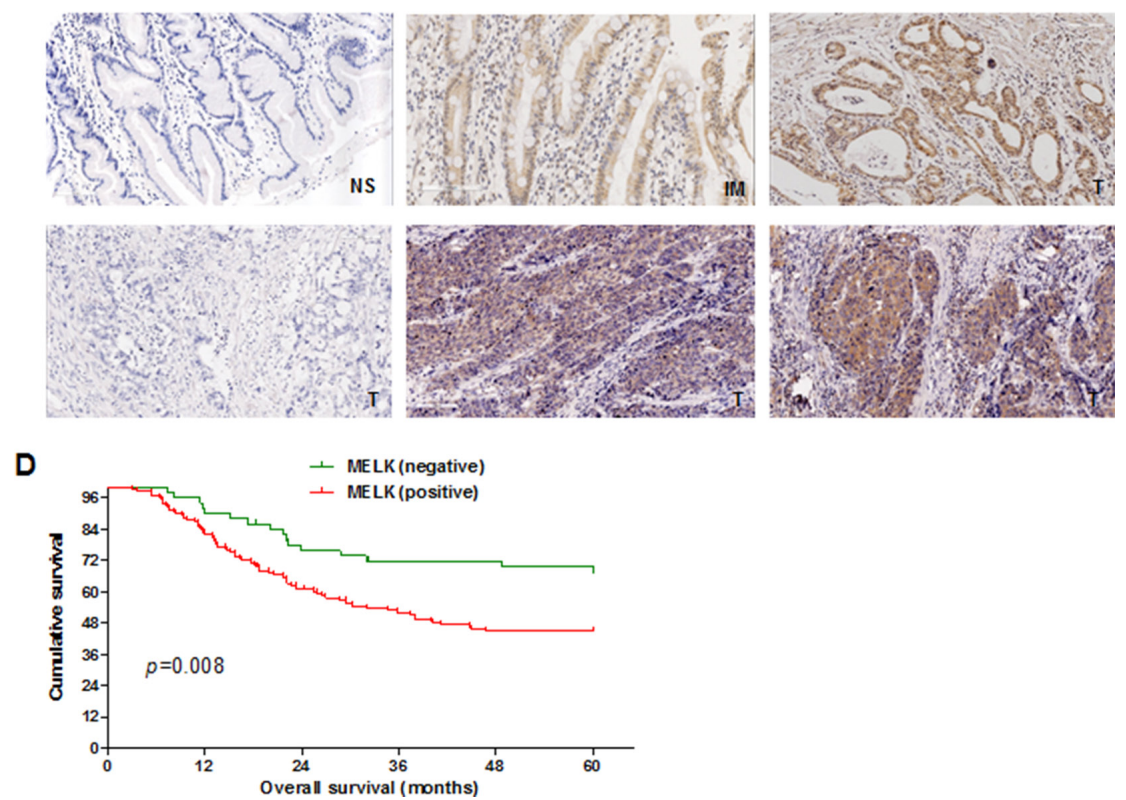

Figure 1: MELK expression in cultured GC cells and primary GC tissues, and survival in patients with GC. A. Western blotting analysis of MELK in GC cell lines. B. MELK expression in primary GC (T) and distal surgical margin normal mucosa (N) were examined by Western blotting. C. Expression of MELK by immunohistochemical staining. Original magnification: 200x. NS: normal stomach; IM: intestinal metaplasia; T: gastric cancer. D. Kaplan-Meier survival curves of overall survival for all patients with MELKnegative vs. -positive GC tissue. 
any of the distal surgical margin samples, indicating that MELK is upregulated in GC tissues compared to normal stomach mucosa.

Next we measured the expression of MELK in primary GC tissues using immunohistochemistry (IHC). MELK was seldom expressed in normal stomach mucosa, but was highly expressed in the cytoplasm of GC tissues (Fig. 1C). MELK was expressed in 71.9\% (128/178) of the GC tumor tissue samples. Of the 104 cases that had adjacent noncancerous mucosa present in the same section, MELK was expressed more frequently in the cancer lesion than the corresponding noncancerous mucosa (68.3\% vs. $28.8 \%, p=0.036$ ) (Table S1). In addition, MELK was expressed in $66.7 \%(12 / 18)$ of gastric intestinal metaplasia (IM) samples, a precancerous lesion of the stomach present in some GC specimens (Fig. 1C).

\section{Overexpression of MELK was associated with lymph node involvement, distant metastasis, and poor prognosis in patients with GC}

To clarify the role of MELK in gastric carcinogenesis, we analyzed the association between MELK expression and clinicopathological characteristics in GC patients. As shown in Table 1, GC patients with lymph node involvement and distant metastasis exhibited higher MELK expression rates than patients without these characteristics $(77.1 \%$ vs. $57.4 \%, p=0.010 ; 91.7 \%$ vs. $68.8 \%, p=0.024$, respectively). Likewise, a larger portion of advanced GC patient tissues expressed MELK compared to early gastric carcinoma tissues (T1 vs. T2$4, p=0.004)$, and expression tended to increase in more advanced TNM stages $(p=0.056)$.

Multivariate analysis of 5-year overall survival (OS) showed that MELK expression was an independent marker for poor prognosis $(p=0.017)$ (Table 2$)$. KaplanMeier survival curves showed that OS was worse in GC patients with MELK expression compared to patients showing no expression ( $p=0.008$, Fig. 1D).

\section{MELK Knockdown attenuated GC cell migration and invasion both in vitro and in vivo}

Since MELK was overexpressed in all GC cell lines examined, we used a loss of function approach in two GC cell types (BGC823 and SGC7901) to determine the role of MELK in gastric tumorigenesis. Knockdown of MELK mRNA expression following infection with a lentivirus expressing anti-MELK small hairpin RNA (shRNA) was confirmed by Western blotting (Fig. 2A); shRNA treatment also reduced, but did not eliminate, MELK protein expression. MELK knockdown resulted in morphological changes in both BGC823 and SGC7901 cells (Fig. 2B). Since $M E L K$ expression was associated with lymph node and distant metastasis in patients with primary GC, it is possible that MELK endows GC cells with invasive behavior. Indeed, wound healing, transwell, and Matrigel invasion assays showed that both BGC823-shMELK and SGC7901-shMELK cells displayed decreased migration and invasion as compared to their respective shControl cells (Fig. 2C-2F, Fig. S2, $p<0.05$ ).

Next, to demonstrate the effect of MELK on metastatic colonization, BGC823-shMELK cells and BGC823-shControl cells were injected into athymic nude mice via the tail vein. Metastatic potential was assessed by counting colonized tumor nodules in the lungs of these mice. BGC823-shMELK-injected mice had fewer lung tumor nodules compared to BGC823shControl-injected mice (Fig. 2G). Collectively, these data indicate that MELK strongly promotes cell migration and invasion in GC.

\section{Targeting MELK reduced GC cell proliferation both in vitro and in vivo}

The effects of MELK knockdown on the proliferation of BGC823 and SGC7901 cells were examined using Cell Counting Kit-8. As shown in Fig. 3A, shRNA-induced MELK knockdown inhibited cell growth. OTSSP167, a small molecular inhibitor (SMI) of MELK, also markedly suppressed proliferation of BGC823 cells in a dose-dependent manner (Fig. S4). The IC50 of OTSSP167 in these cells was $25 \mathrm{nM}$ as determined using an xCELLigence real-time cell analyzer (RTCA).

In a xenograft experiment, BGC823-shControl and BGC823-shMELK cells were subcutaneously injected into the right hind legs of the nude mice. Tumors were smaller and their growth was slower in the BGC823-shMELKinjected group compared to the BGC823-shControlinjected group (Fig. 3B). Thus, MELK knockdown inhibited GC cell viability and proliferation both in vitro and in vivo.

\section{Inhibition of MELK induced apoptosis and G2/M arrest in GC cells}

To determine whether MELK inhibits cell growth by triggering apoptosis or suppressing DNA synthesis, we monitored cell cycle progression after MELK knockdown using Fluorescence-activated cell sorting (FACS). A higher proportion of cells infected with shMELK lentivirus were arrested in the G2/M phase of the cell cycle compared to those infected with scrambled shControl $(39.67 \%$ vs. $8.66 \%$ in BGC823 cells, and $17.57 \%$ vs. $11.60 \%$ in SGC7901 cells, respectively, Fig. 4A upper panel, Fig. 4C left panel, and Fig. S3A). The increase in the G2/M phase population was accompanied by a decrease in the number of cells in the S-phase. Targeting MELK enzymatic activity with $25 \mathrm{nM}$ and $50 \mathrm{nM}$ OTSSP167 also increased the $\mathrm{G} 2 / \mathrm{M}$ phase population compared to vehicle treatment (57.88\% vs. $9.83 \%$ in BGC823 cells, and $21.37 \%$ vs. 


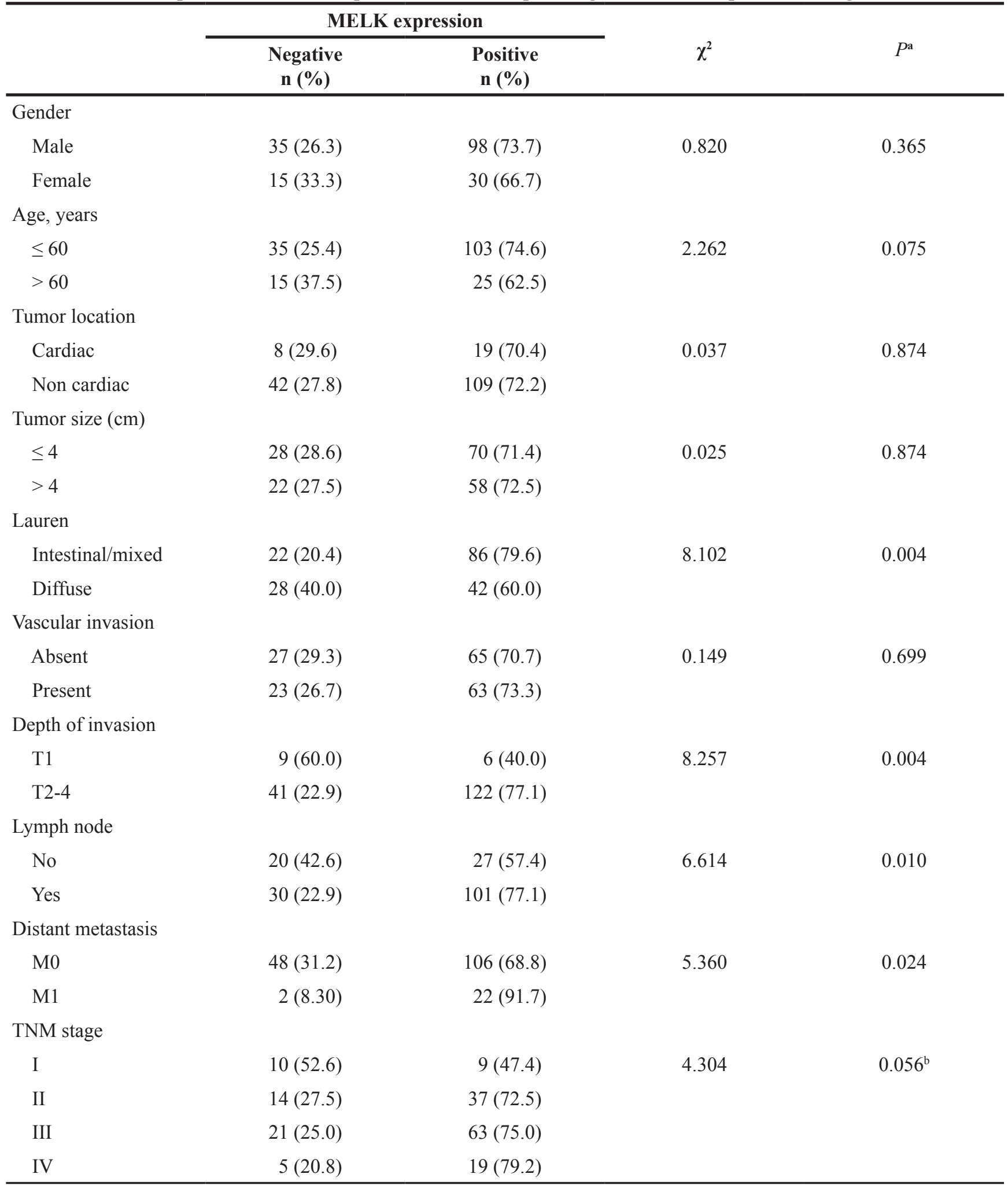

${ }^{\mathrm{a}}$ Chi-square test, ${ }^{\mathrm{b}}$ Kruskal-Wallis Test; - negative; + positive

9.83\% in SGC7901 cells, respectively, Fig. 4A lower panel, Fig. 4C right panel, and Fig. S3B). Apoptosis was assessed by annexin V and PI staining in BGC823 and SGC7901 cells treated with vehicle or $25 \mathrm{nM}$ or $50 \mathrm{nM}$
OTSSP167. OTSSP167 treatment increased apoptosis in a dose-depended manner compared to vehicle treatment $(16.9 \%$ vs. $4.2 \%$ for BGC 823 and $23.47 \%$ vs. $4.7 \%$ for SGC7901, $p<0.05$ ) (Fig. 4B and 4D). These data suggest 
Table 2: Results of univariate and multivariate Cox proportional-hazards regression analysis for overall survival of GC patients

\begin{tabular}{|c|c|c|c|c|}
\hline & Univariate & & Multivariate & \\
\hline Parameter & $\begin{array}{c}\text { 5-year survival rate } \\
(\%) \\
(\text { mean } \pm \text { S.E) }\end{array}$ & $P$ & RR 95\% CI & $P$ \\
\hline Tumor size $(\mathrm{cm})$ & & 0.008 & $1.380(0.892-2.136)$ & 0.148 \\
\hline$\leq 4$ & $60.0 \pm 0.050$ & & & \\
\hline$>4$ & $40.2 \pm 0.056$ & & & \\
\hline Vascular invasion & & 0.001 & $1.198(0.748-1.919)$ & 0.453 \\
\hline Absent & $62.0 \pm 0.051$ & & & \\
\hline Present & $39.3 \pm 0.054$ & & & \\
\hline Depth of invasion & & 0.001 & $1.711(1.125-2.602)$ & 0.012 \\
\hline $\mathrm{T} 1$ & $100 \pm 0.000$ & & & \\
\hline $\mathrm{T} 2-4$ & $46.6 \pm 0.039$ & & & \\
\hline $\begin{array}{l}\text { Lymph node } \\
\text { involvement }\end{array}$ & & 0.000 & $1.503(1.201-1.811)$ & 0.000 \\
\hline No & $74.5 \pm 0.064$ & & & \\
\hline Yes & $42.6 \pm 0.044$ & & & \\
\hline Distant metastasis & & 0.000 & $4.588(2.572-8.182)$ & 0.000 \\
\hline M0 & $57.3 \pm 0.040$ & & & \\
\hline M1 & $0.00 \pm 0.000$ & & & \\
\hline MELK expression & & 0.008 & $1.950(1.129-3.368)$ & 0.017 \\
\hline Negative & $67.5 \pm 0.067$ & & & \\
\hline Positive & $44.8 \pm 0.044$ & & & \\
\hline Gender & & 0.154 & - & - \\
\hline Male & $47.8 \pm 0.044$ & & & \\
\hline Female & $61.3 \pm 0.074$ & & & \\
\hline Age, years & & 0.679 & - & - \\
\hline$\leq 60$ & $47.4 \pm 0.081$ & & & \\
\hline$>60$ & $47.4 \pm 0.081$ & & & \\
\hline
\end{tabular}

$\mathrm{RR}$, relative risk; CI, confidence interval.

that MELK promotes GC cell survival and proliferation by accelerating transition out of the G2/M phase and by reducing apoptosis.

\section{MELK may facilitate epithelial-mesenchymal transition (EMT) in GC cells}

Enhanced cell migration and invasion capabilities are important consequences of EMT, an early event in tumor metastasis. Here, we found that MELK depletion in BGC823 and SGC7901 cells changed cell morphology from an elongated spindle-like appearance to a cobblestone-like appearance (Fig. 2B). Morphological alteration is one of the main features of EMT. Therefore, we examined the expression of markers associated with EMT by Western blotting. MELK depletion upregulated E-cadherin and downregulated N-cadherin, Vimentin, and Snail in both BGC823 and SGC7901 cells (Fig. 5A). Thus, MELK expression may contribute to metastasis and poor prognosis in patients with primary GCs by promoting EMT in GC cells. 
A
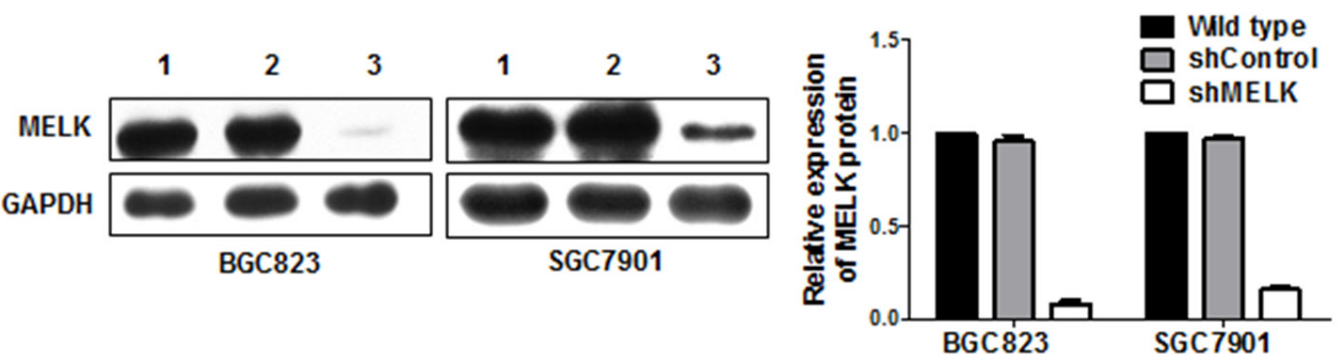

B

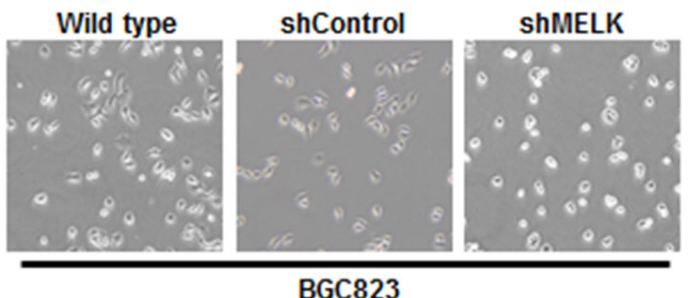

C
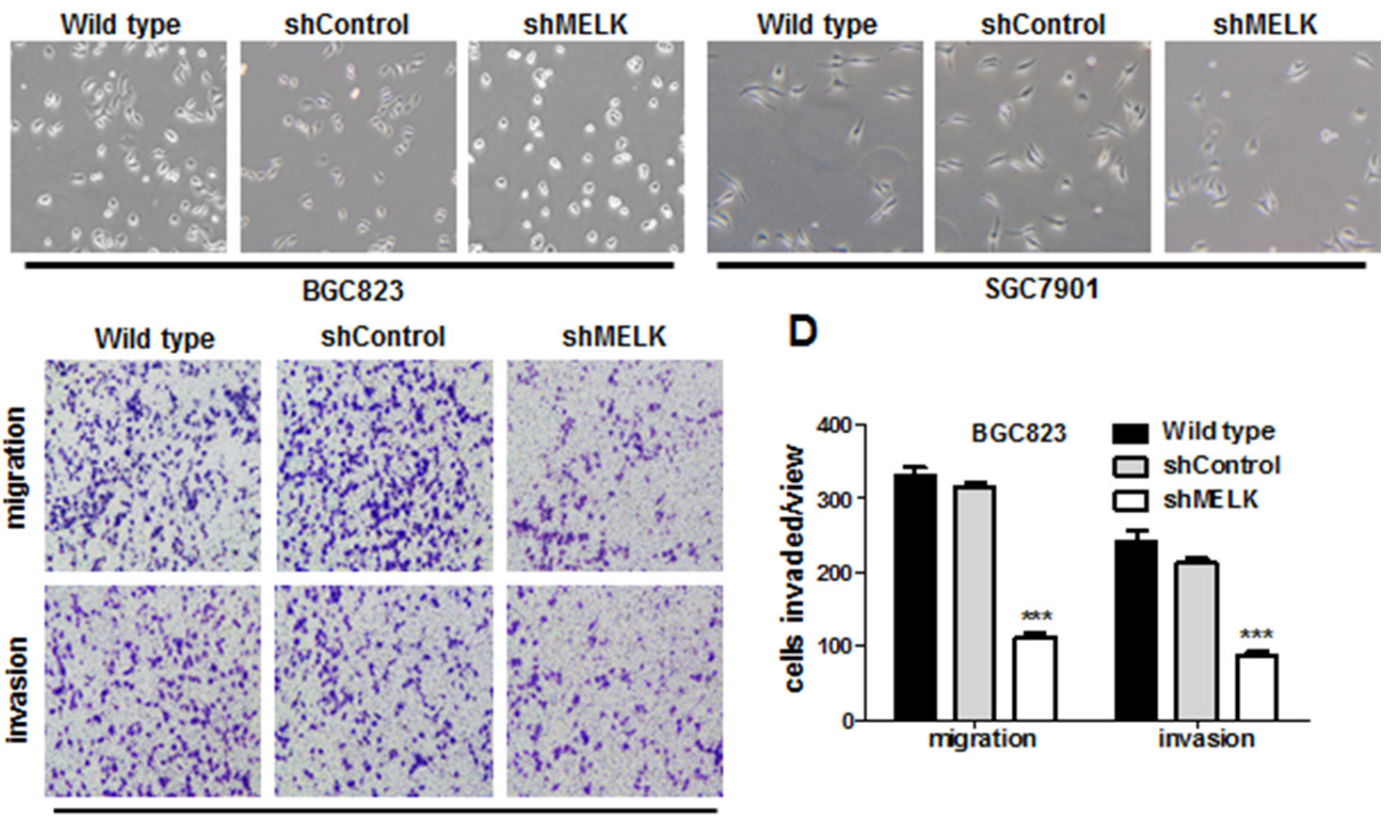

\section{흘}

E
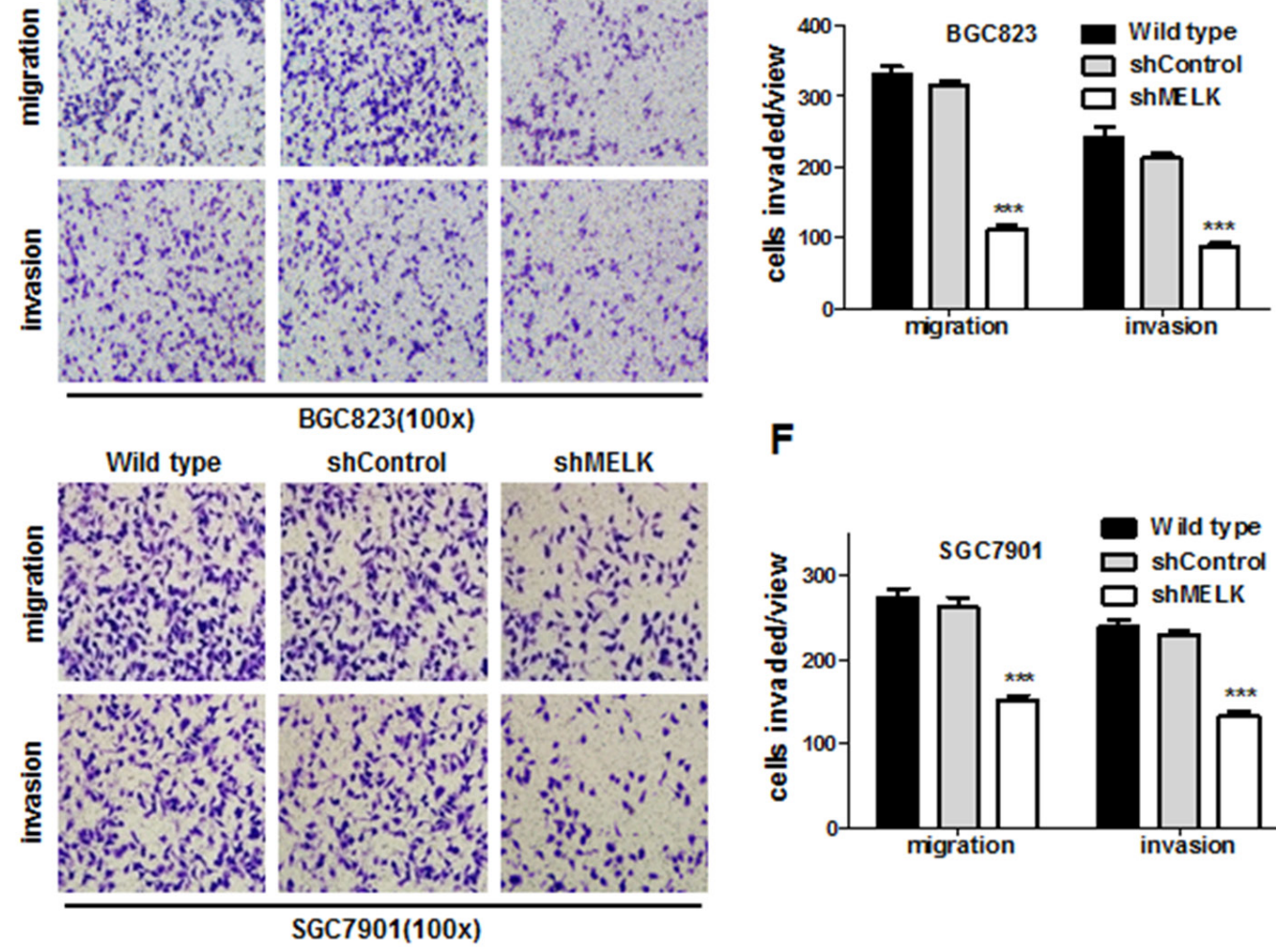

$\mathbf{F}$

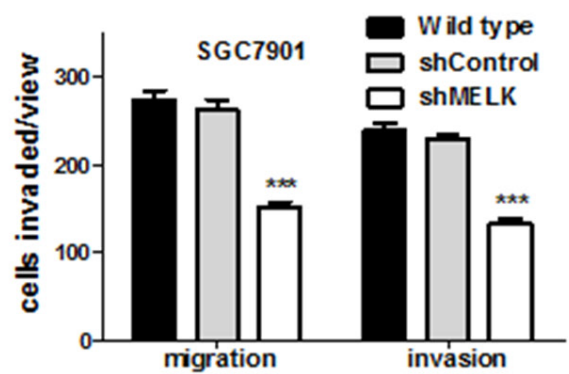

G
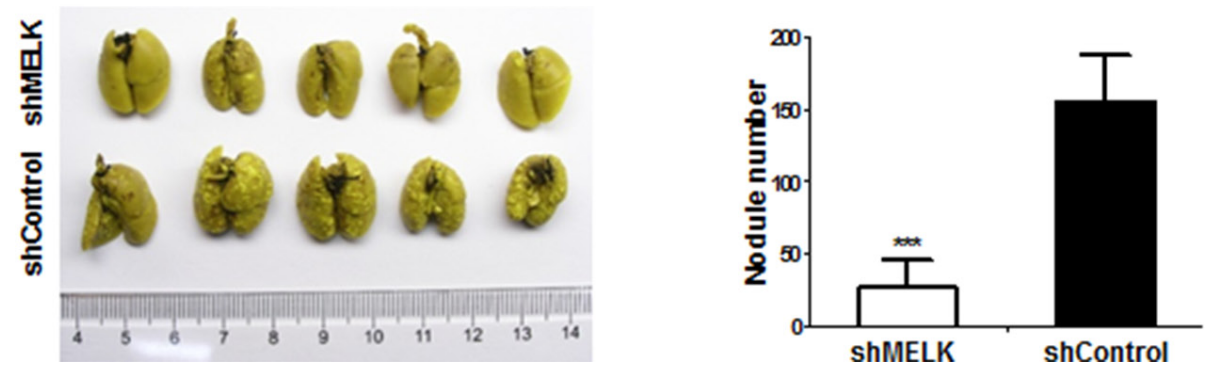

Figure 2: MELK knockdown attenuated migration and invasion of GC cells in vitro and in vivo. A. MELK protein expression. Lane 1, wild type; Lane 2, scrambled shControl; Lane 3, shMELK. B. Morphologic changes in GC cells in response to MELK knockdown. Original magnification: $\times 100$. C-F. BGC823 and SGC7901 cells were assayed for their invasive capability on Matrigel or Boyden chambers. Bars represent the mean \pm SD of three independent experiments. G. The effect of MELK on metastatic colonization through blood circulation. ${ }^{*} \mathrm{p}<0.05,{ }^{* *} \mathrm{p}<0.01,{ }_{* * *} \mathrm{p}<0.001$. 


\section{MELK activated Akt signaling via phosphorylation}

Activity of the oncogenic kinase Akt is most commonly associated with GC [23], and the PI3K/ Akt axis is emerging as a central promoter of EMT [24]. Both MELK and Akt are serine/threonin kinases, and it is possible that MELK might activate Akt. There were no differences in total Akt protein levels among MELK-shRNA, scrambled shControl, or wild-type cells. However, MELK knockdown decreased levels of phosphorylated Akt (Ser-473) protein compared to scrambled control-treated or wild-type cells (Fig. 5B). Treatment with LY294002, a PI3K inhibitor, similarly reduced Akt phosphorylation and altered EMT-associated protein levels in BGC823 cells (Fig. 5C). Together, these data suggest that MELK is involved in the PI3K/Akt signal cascade and that MELK may induce EMT by activating Akt. Further study is required to determine whether Akt is a direct substrate of MELK.

\section{Efficacy of OTSSP16 treatment in preclinical GC patient-derived xenograft (PDX) mouse models}

Two MELK-positive, and one MELK-negative, GCPDX models were chosen from our established banks to evaluate whether MELK is an effective therapeutic target for $\mathrm{GC}$ in vivo (Fig. 6A, 6B, and 6C). Third generation PDX mice were used in this experiment. When the TumorGraft volume reached $100-200 \mathrm{~mm}^{3}$, the PDX mice were intravenously treated with OTSSP $167(15 \mathrm{mg} /$ $\mathrm{kg}$ ) or vehicle once every other day for two weeks. The reaction to OTSSP167 was quantified by tumor growth inhibition (TGI). In the two MELK-positive models, TGI values were $106 \%$ and $112 \%$ at the end of drug administration (Fig.6D and 6E, right panel). In the MELKnegative model, the TGI value was only $19 \%$ (Fig. 6 F, right panel). MELK expression levels in the TumorGraft tissues were subsequently evaluated by IHC. In both MELK-positive cases, MELK expression was eliminated in the TumorGraft after OTSSP167 treatment but not after
A

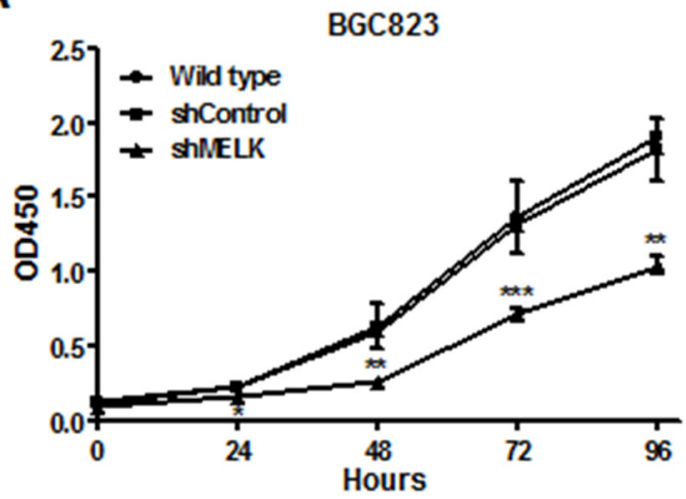

B

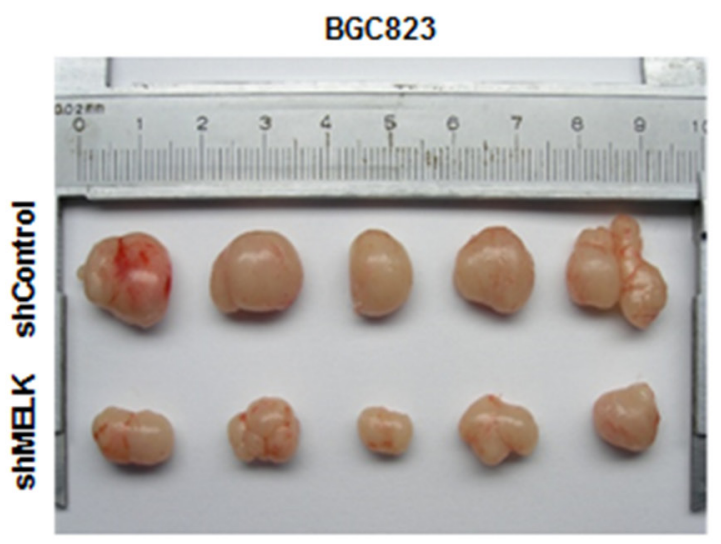

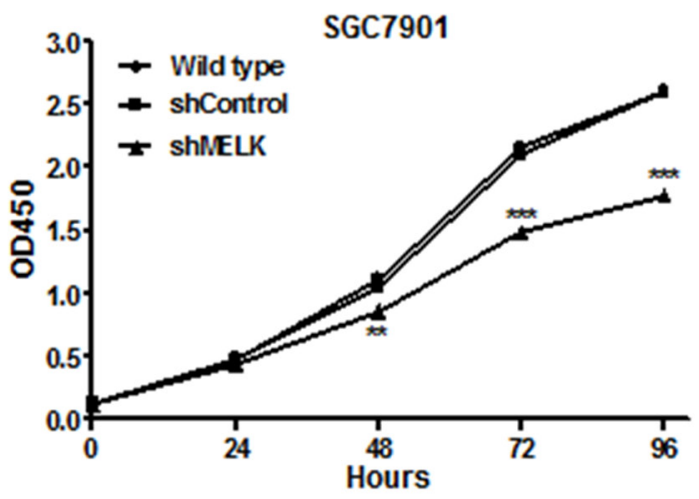

BGC823

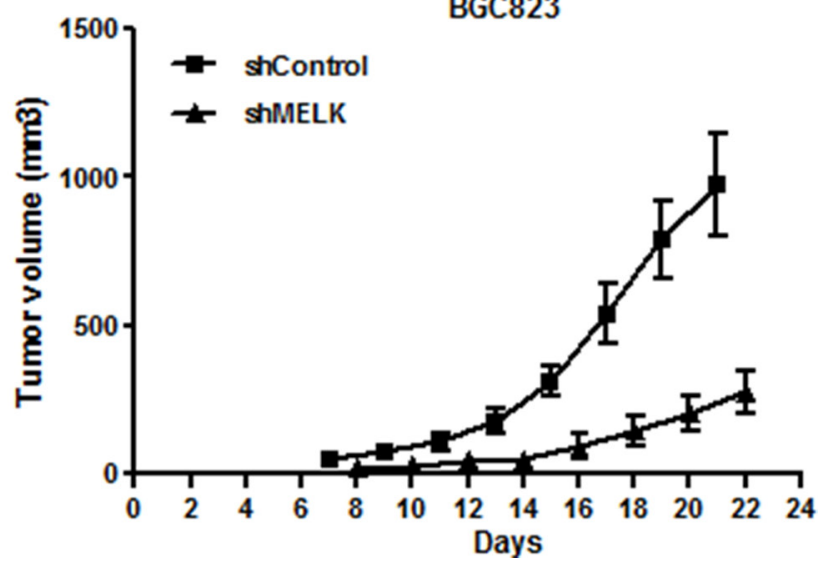

Figure 3: Effects of MELK knockdown on GC cell growth in vitro and in vivo. A. Cell proliferation assay using a Cell Counting Kit-8. B. Photograph showing tumor formation in nude mice injected with BGC823-shContral and shMELK, as well as tumor growth curve. The data are shown as mean $\pm \mathrm{SD}$. ${ }^{*} \mathrm{p}<0.05,{ }^{* *} \mathrm{p}<0.01,{ }^{* * *} \mathrm{p}<0.001$. 
vehicle treatment (Fig. 6D and 6E, middle panel). These data strongly suggest that MELK might be an effective molecular target for the treatment of gastric cancer.

\section{DISCUSSION}

Elevated MELK expression has been identified in a variety of tumors and is associated with poor prognosis in cancer patients. Our previous Affimetrix HG-133 array data showed that $M E L K$ is strongly upregulated in GC tumors as compared to normal gastric tissue. Here, we found that MELK was frequently overexpressed in primary GC tissues, but was not detected in normal gastric tissues. These findings are similar to the results recently reported by Du et al. [12].

We also analyzed the association between MELK expression and clinicopathologic factors. MELK expression was positively correlated with lymph node involvement,
A
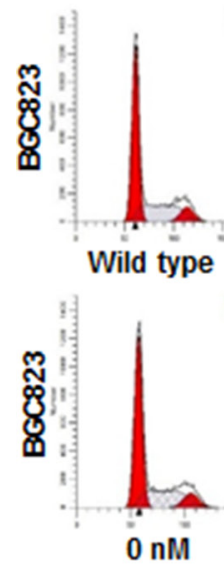
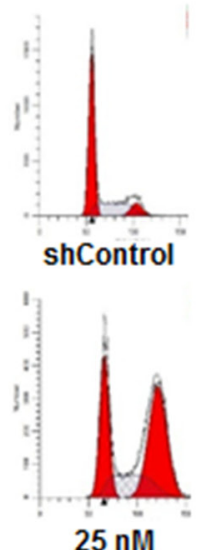

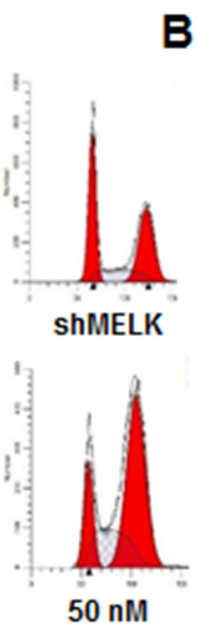

B

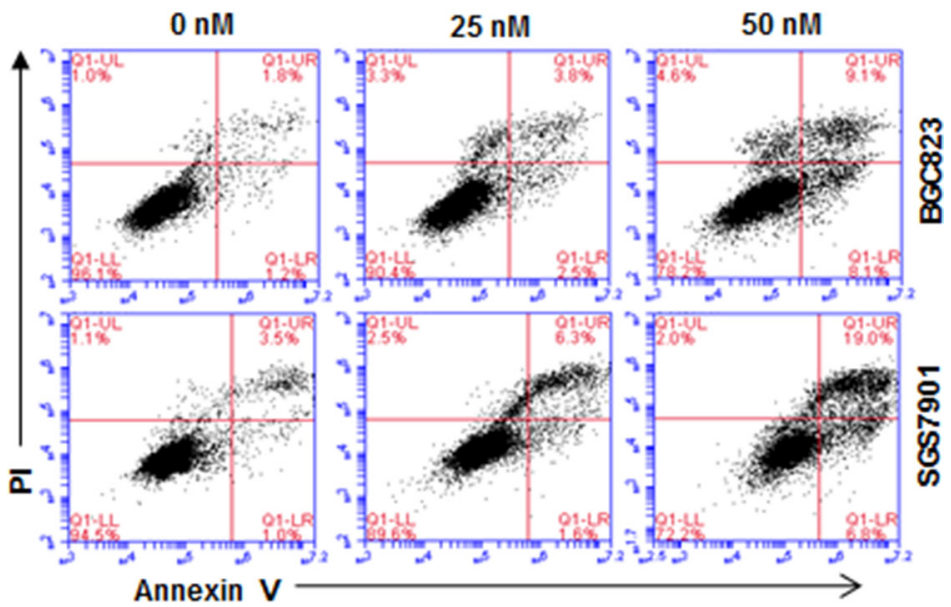

C
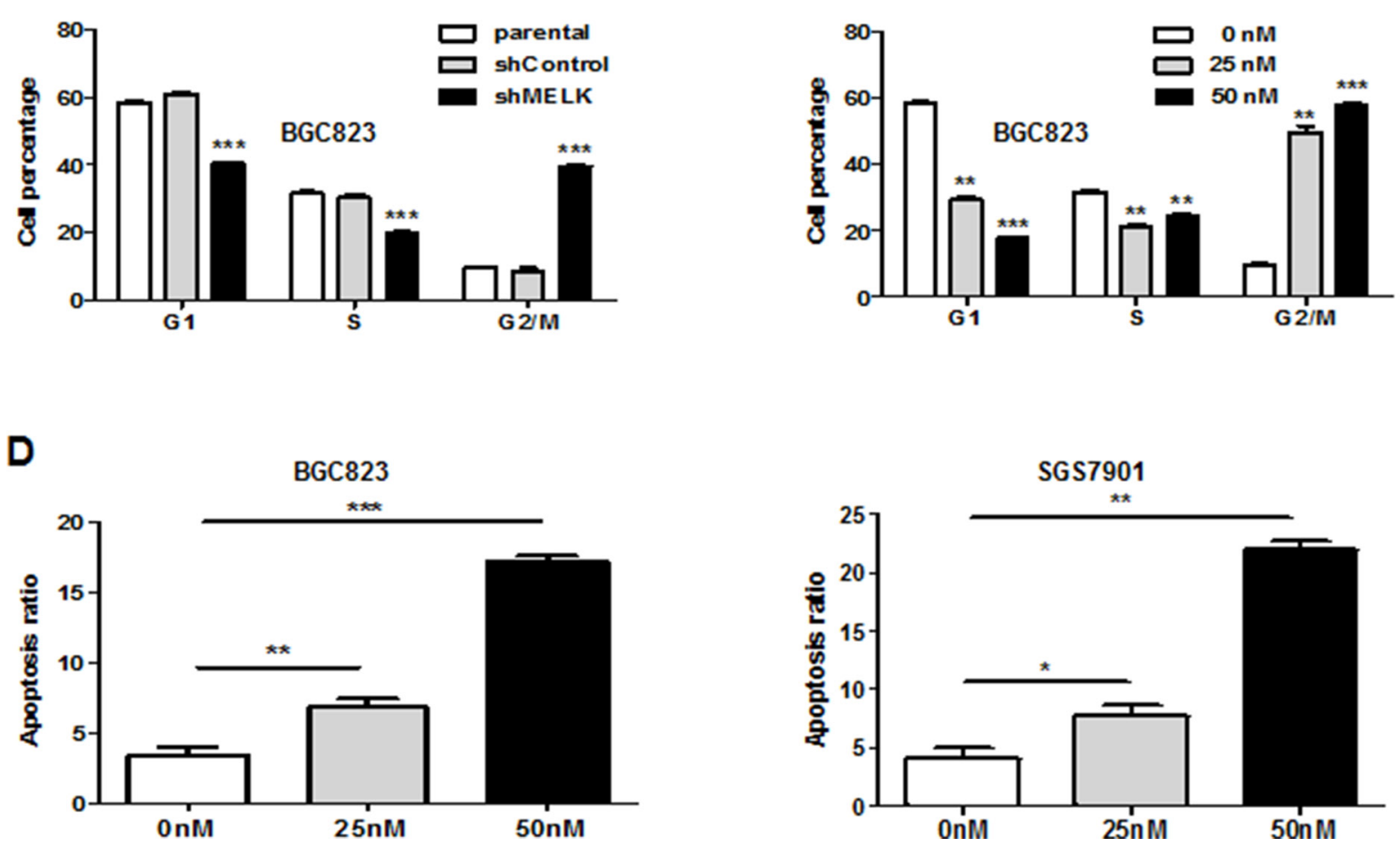

Figure 4: Targeting MELK expression or MELK kinase activity results in G2/M arrest and apoptosis. A. Cell cycle analysis by Flow cytometry. B. Apoptosis assessed by Annexin V and PI staining in BGC823 and SGC7901 cells treated with different concentrations of OTSSP167. C. Histogram of cell cycle distribution. Bars, mean \pm SD of three independent experiments. D. Histogram of cell apoptosis. Bars, mean $\pm \mathrm{SD}$ of three independent experiments. ${ }^{*} \mathrm{p}<0.05,{ }^{* *} \mathrm{p}<0.01,{ }^{* * *} \mathrm{p}<0.001$. 
distant metastasis, and more advanced cancer stages. Furthermore, elevated MELK expression was negatively correlated with 5-year survival rate, which is consistent with the prognosis for breast cancer, prostate cancer, and glioblastoma with elevated MELK expression [8, 17, 25].

Because MELK was overexpressed in all of the GC cell lines examined, we applied two loss-of- functioning approaches. Reducing $M E L K$ expression using shRNA or inhibiting MELK kinase activity using OTSSP167 reduced the growth and invasiveness in GC cells. MELK expression is normally restricted to areas where mesenchymal-epithelial interactions are taking place during the later stages of embryogenesis [7], and MELK knockdown triggered morphological changes
A

B

adherin

N-cadherin

Vimentin

Snail

GAPDH
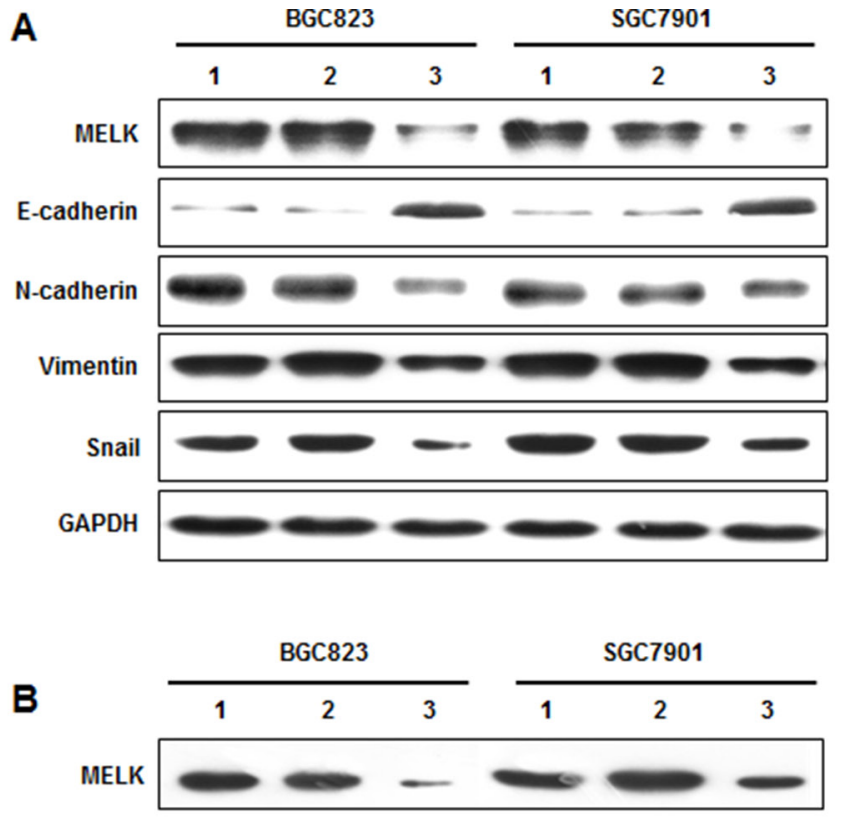

P-Akt (S473)

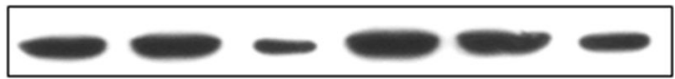

Akt

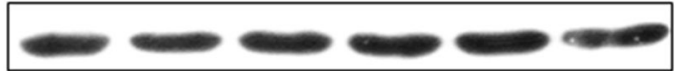

GAPDH

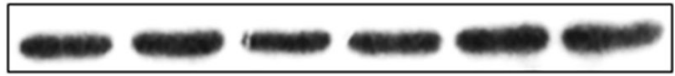

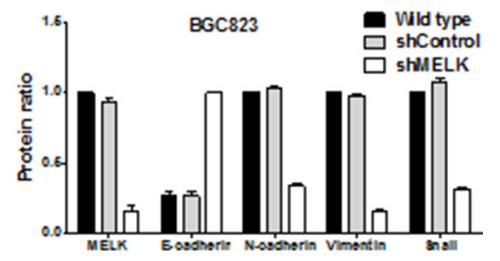
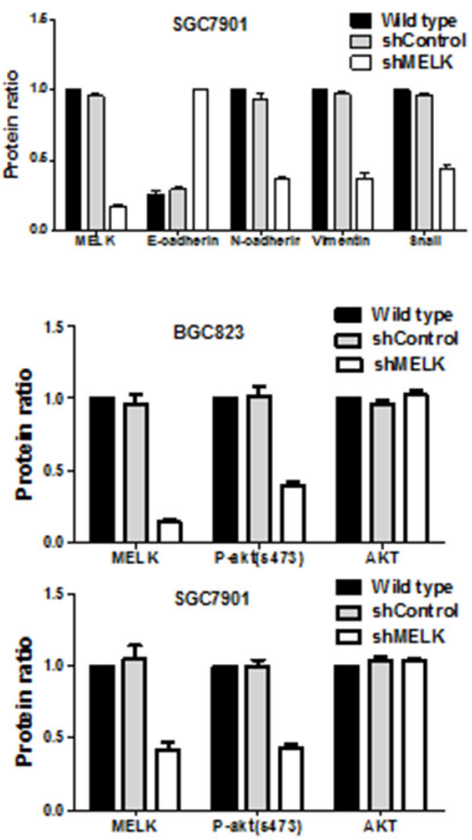

C

P-Akt ( 5473$)$
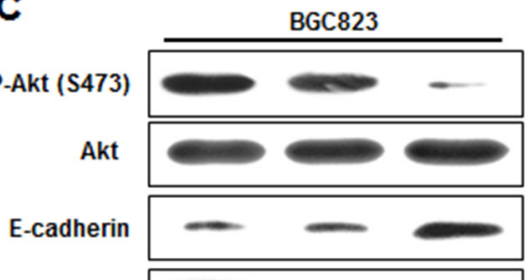

N-cadherin

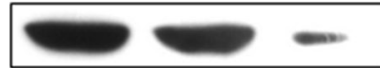

Vimentin

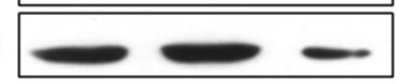

Snail

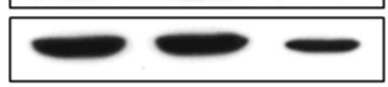

GAPDH
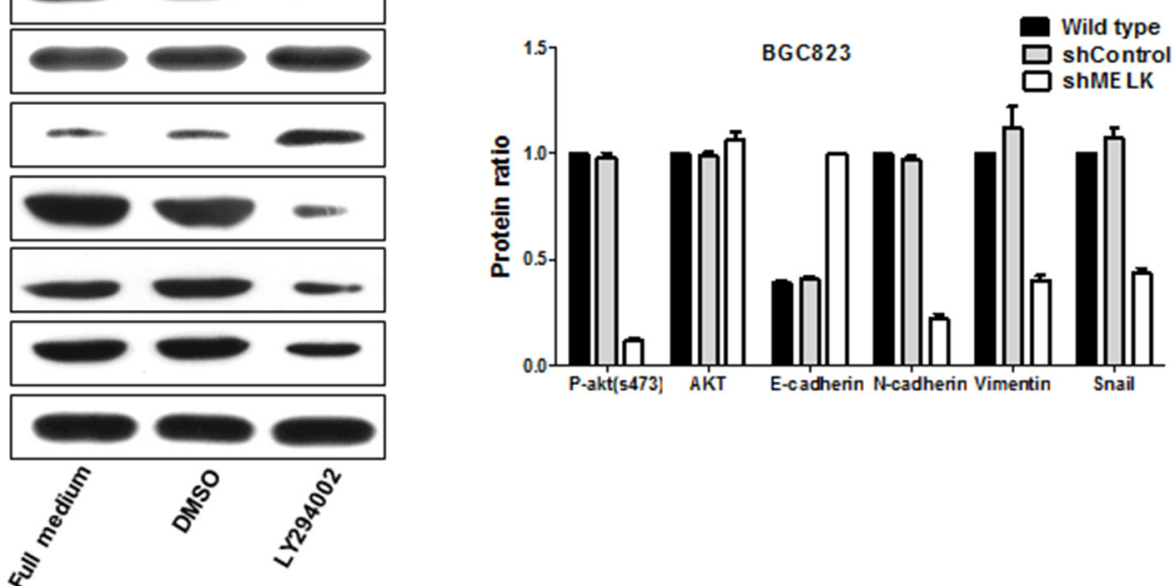

Figure 5: MELK regulates the expression of EMT-associated proteins and AKT activity. A and B. Expression profiles of EMT components in response to MELK knockdown determined using Western blotting. Lane 1, wild type; Lane 2, scrambled shControl; Lane 3, shMELK. (C) Altered expression of EMT-associated proteins and Akt activity in BGC823 cells treated with LY294002. 
A
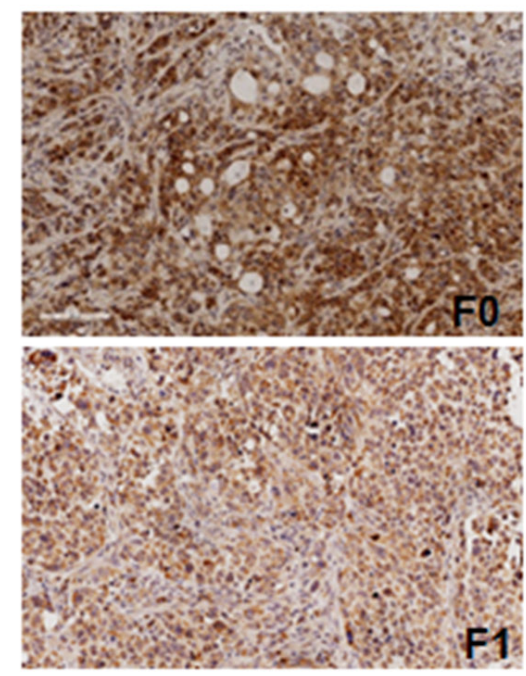

B
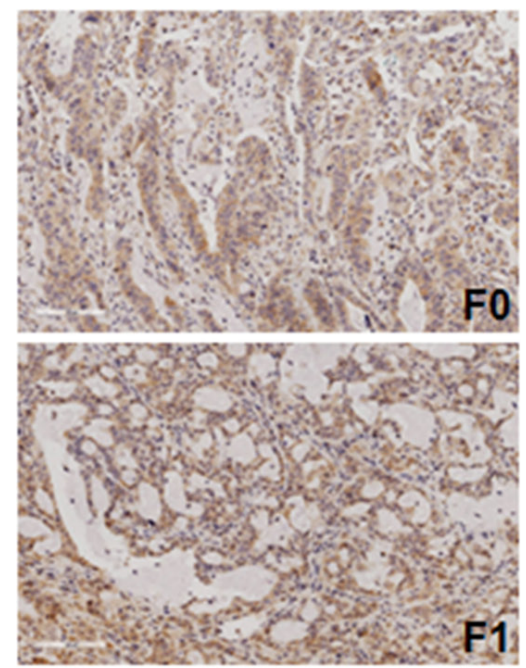

C
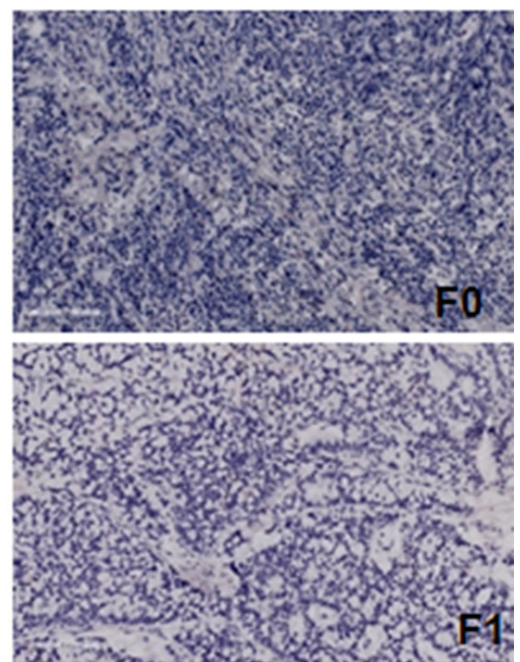

D

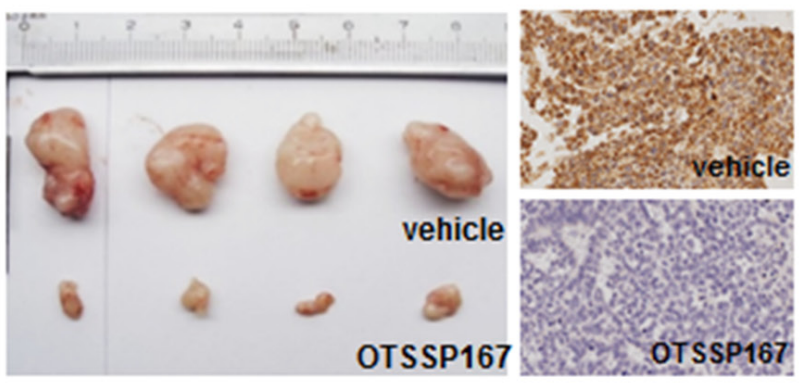

E

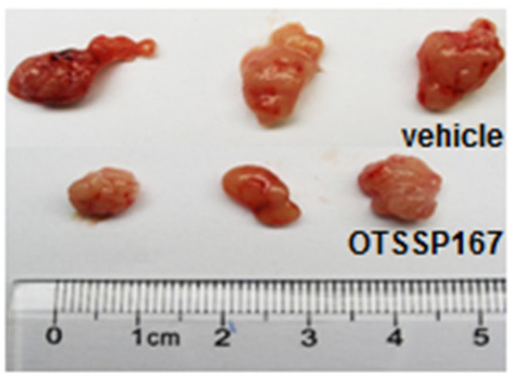

$\mathbf{F}$

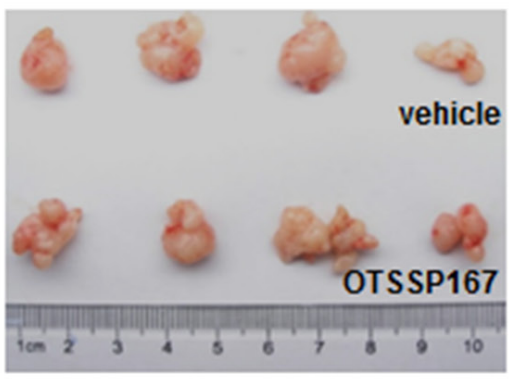

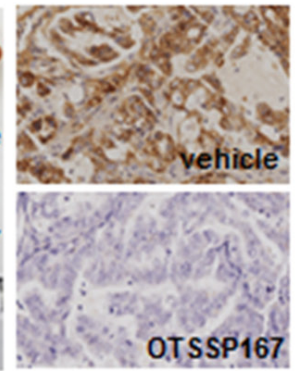

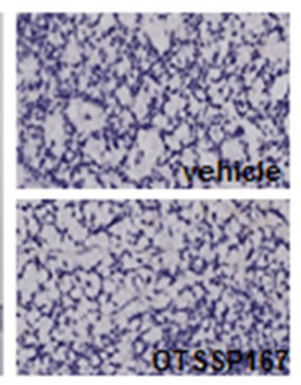

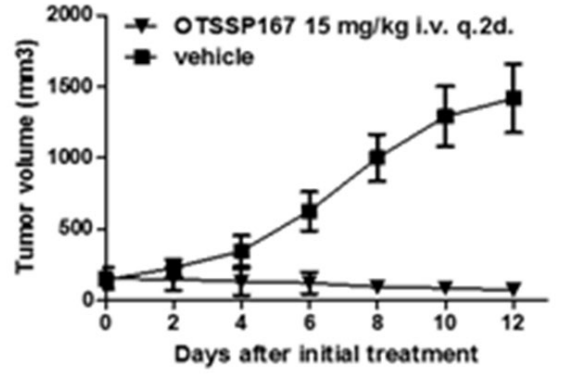
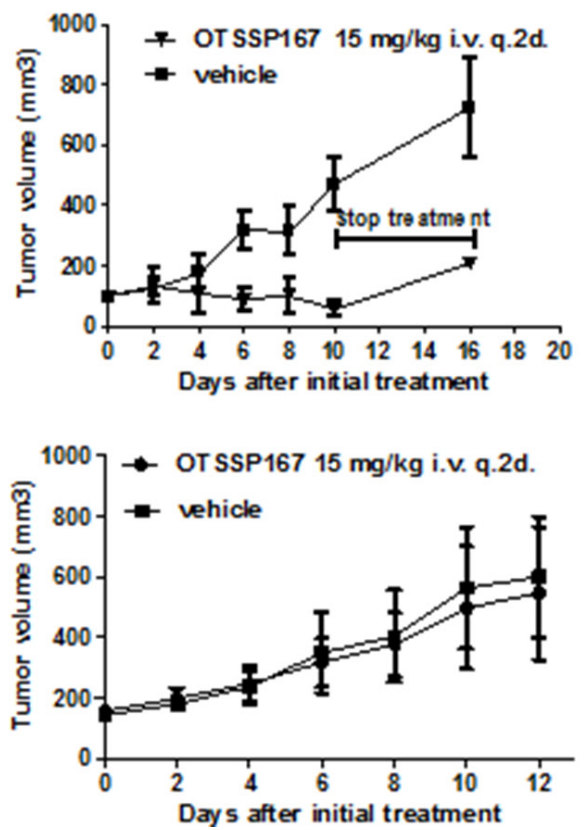

Figure 6: OTSSP167 reduces growth of MELK-positive GC-PDX TumorGraft. A, B and C. IHC for MELK in patients' tumors. A. MELK-positive staining in the case \#1 GC patient-derived TumorGraft. B. MELK-positive staining in the case \#3 GC patientderived TumorGraft. C. MELK-negative staining in the case \#2 GC patient-derived TumorGraft. F0, primary GC tissue; F1, $1^{\text {st }}$ generation of TumorGraft. Original magnification: 200x. D, E and F. NOD/SCID mice bearing TumorGraft of the F3 generation were intravenously treated with OTSSP167 or vehicle control once every two days for two weeks. Tumor volume was measured every two days (right panel), and MELK expression in TumorGraft tissue after treatment was detected by IHC (middle panel). Tumor volume is shown as mean \pm SD. 
in GC cells. We therefore hypothesized that MELK may promote EMT, a key step in tumor cell migration. As expected, MELK knockdown altered expression of EMT-associated proteins. Thus, MELK expression may contribute to metastasis and poor prognosis in primary GC by promoting EMT.

TumorGrafts derived from surgical specimens conserve inter-individual diversity, microscopic fidelity, and genetic heterogeneity of the original primary tumors [26-29]. Personalized TumorGrafts have been used as an investigational platform for therapeutic decision-making that can guide treatment for individual patients, and treatments identified in this way generally elicit favorable clinical responses [30-33]. We used previously established GC-PDX models to verify the preclinical efficacy of MELK-targeting therapy in GC. We found that OTSSP167 had a strong antitumor effect in MELK-positive, but not in MELK-negative, GC-PDX models. Characterization of the immune system in MELK knockout mice indicates that MELK is not essential for proper bone marrow function [34]. Bone marrow toxicity is a major adverse effect of many anti-cancer therapies, especially with drugs that target mitotic kinases. MELK may therefore prove to be a promising, highly-selective target for treatment with few negative side effects.

Although MELK-targeting therapy in PDX models markedly suppressed tumor growth, it also resulted in modest body weight loss (less than 20\%). However, in one of the MELK-positive tumor models, all PDX mice showed obvious body weight loss, regardless treatment. These observations might be explained by cachexia due to the severity of the primary tumors, but future studies should address the impact of treatments that reduce MELK activity on other indicators of health, including body weight.

In summary, MELK is frequently upregulated in both human GC cell lines and primary GC tissues, and its expression correlates with metastasis and a poor prognosis in GC patients. Importantly, reducing MELK expression or inhibiting kinase activity increased G2/M arrest and apoptosis, thereby inhibiting GC cell growth both in vitro and in vivo. MELK knockdown also inhibited invasive behavior in GC cells and decreased metastatic colonization in xenograft models. Notably, we demonstrated for the first time that MELK activity upregulates EMT. Furthermore, we showed that reducing MELK activity with OTSSP167 has anticancer effects in preclinical GC-PDX murine models. Our findings suggest that clinical evaluation of MELK-targeting therapies is warranted as a novel treatment strategy for GC patients.

\section{MATERIALS AND METHODS}

\section{Cell culture and reagents}

AGS, SNU1, MKN45, and 293T cell lines were purchased from ATCC (Manassas, VA, USA). MKN28 and
NUGC3 cell lines were obtained from the Health Science Research Resources Bank (Tokyo, Japan). BGC823, MGC803, and SGC7901 cell lines were obtained from the Cell Research Institute (Shanghai, China). The cells were cultured in RPMI-1640 medium (GIBCO, Carlsbad, NY, USA), supplemented with $10 \%(\mathrm{v} / \mathrm{v})$ fetal calf serum (GIBCO, NY, USA) and antibiotics at $37^{\circ} \mathrm{C}$ in a humidified $5 \% \mathrm{CO}_{2}$ atmosphere.

Antibodies for Vimentin, E-cadherin, N-cadherin, Akt, phospho-Akt (Ser-473), ERK1/2, phospho-ERK1/2 (Thr-202/Tyr-204), Snail, and GAPDH were purchased from Cell Signaling Technology (Beverly, MA). AntiMELK antibody and puromycin were purchased from Sigma-Aldrich (St. Louis, MO, USA). OTSSP167 was purchased from Medchem Express (Beijing, China).

\section{RNA isolation and polymerase chain reaction (PCR)}

Total RNA was extracted using TRIzol reagent (Invitrogen, Carlsbad, CA, USA) and reverse transcribed into cDNA using M-MLV reverse transcriptase (Promega, Madison, WI, USA) according to the manufacturer's instructions. GAPDH was used as an internal control. The primer sequences used are listed below: MELK: forward primer: 5'-GCTGCAAGGTATAATTGATGGA-3', reverse primer: 5'-CAGTAACATAATGACAGATGGGC-3'.

\section{Patients and gastric tissue specimens}

A total of 178 paraffin-embedded GC tissues were collected from GC patients who underwent radical gastrectomy at Peking University Beijing Cancer Hospital between January 2003 and December 2007. Additionally, eight surgically removed frozen (stored at $-70^{\circ} \mathrm{C}$ ) GC samples and corresponding surgical margins collected in November 2014 were obtained from the BioBank of Beijing Cancer Hospital. All patients signed informed consent forms, and the Ethics Committee of Beijing Cancer Hospital approved tissue collection. Clinicopathological and follow-up information was obtained from patient data. Gastric cancer stage was classified according to the 2010 tumor-node metastasis (TNM) classification recommended by the American Joint Committee on Cancer (AJCC $7^{\text {th }}$ edition). T and $\mathrm{N}$ classification were assessed based on the final pathological result and $\mathrm{M}$ classification was determined by surgical findings. Early gastric cancer (EGC) was defined as a tumor that was confined to the mucosa or submucosa regardless of lymph node (LN) involvement. Advanced gastric cancer (AGC) was defined as a tumor that invaded the muscle proper or beyond. Overall survival (OS) was calculated beginning from the date of the initial surgery and ending either at the time of death caused by the tumor or at the date of the last follow-up. All patients were tracked until 2012. None of the patients received chemotherapy or radiation therapy prior to surgery. 
This study was performed with the approval of the Ethics Committee of Peking University Beijing Cancer Hospital.

\section{Immunohistochemistry}

Four-micrometer sections from formalin-fixed paraffin-embedded (FFPE) tissues were deparaffinized in xylene and rehydrated through graded alcohol washes. Antigen retrieval was performed by autoclaving in $0.01 \mathrm{M}$ citrate buffer ( $\mathrm{pH} 6.0$ ) for 3 minutes, followed by immersion in 3\% hydrogen peroxide in methanol for 10 minutes to block endogenous peroxidase activity. The sections were then blocked with normal sheep serum (DAKO, Hamburg, Germany) for 90 minutes at room temperature and then incubated with MELK polyclonal antibody (Sigma-Aldrich, St. Louis, MO, USA) diluted at 1:300 overnight at $4^{\circ} \mathrm{C}$. Diaminobenzidine was used as a chromogen, followed by counterstaining with hematoxylin. Samples were considered MELK-positive when $10 \%$ or more of the cancer cells had cytoplasmic MELK staining. The expression of MELK was assessed independently by two experienced pathologists who were blind to the patients' clinical outcomes. There was a high level of consistency between the two pathologists, and in the few discrepant cases $(<5 \%)$ a consensus was reached after joint review.

\section{Lentiviral vector transduction of GC cells to stably silence MELK}

The MELK expression knockdown procedure was conducted as previously described [35]. Lentivirus was produced by the co-transfection of 293T cells with a pLenti vector (pGLV3-shControl or pGLV3-shMELK) and lentiviral packaging mix (Invitrogen, Carlsbad, CA, USA) according to the manufacturer's instructions. Lentivirus-containing supernatant was harvested at 48 hours post-transfection, centrifuged, and stored at $-80^{\circ} \mathrm{C}$. For viral transductions, $1 \mathrm{ml}$ of the scrambled shControl or shMELK lentiviruses was incubated with BGC823 and SGC7901 cells overnight at $37^{\circ} \mathrm{C}$ in a humidified cell culture incubator. Stable GC cells with depleted endogenous MELK expression were selected by culturing in puromycin $(0.8 \mu \mathrm{g} / \mathrm{ml})$.

\section{Cell proliferation assay}

Cell proliferation was measured using a Cell Counting Kit-8 (CCK-8) (Dojindo, Japan) according to the manufacturer's protocol. $2 \times 10^{3}$ cells/well for BGC 823 and SGC7901 were incubated in 96-well plates (CorningCostar, NY, USA) for 24, 48, 72, and 96 hours. $10 \mu \mathrm{l}$ of the CCK-8 solution was added to each well and the plates were incubated for 2 more hours at $37^{\circ} \mathrm{C}$. Absorbance values of all wells were then measured with a reference wavelength of $450 \mathrm{~nm}$ in a Microplate Reader (Bio-Rad, USA).

\section{Cell migration and invasion assay}

Cell migration was assessed with a wound-healing assay. BGC823 and SGC7901 cells were incubated in a 6-well plate (Corning-Costar, NY, USA), and the confluent cell surface was then scratched with a pipette tip. The wound width was recorded using a microscope at 24 and 48 hours. For trans-well chamber-based migration and invasion assays, $5 \times 10^{4}$ cells were loaded into an insert, provided with serum-free medium, and allowed to pass through a polycarbonate filter, which had been either precoated with $100 \mu \mathrm{g}$ of Matrigel (Becton Dickinson, San Jose, CA) for the invasion assay or left uncoated for the migration assay. The lower chambers were filled with DMEM and $10 \%$ FBS. Cells on the upper surface of the filters were wiped out after 24 hours (migration assay) or 72 hours (invasion assay). The membranes were fixed with methanol for 10 minutes and stained with $0.5 \%$ crystal violet for 10 minutes. The cells on the underside of the filter were counted in five randomly selected microscopic views.

\section{Western blot analysis}

The protein expression levels of GC cell lines and primary GC tissues were analyzed by Western Blotting. Cells were lysed in pre-chilled RIPA lysis buffer (Pierce Biotechnology, Rockford, IL) containing protease inhibitor cocktail (Roche, Basel, Switzerland) for 30 minutes, then centrifuged at $15,000 \mathrm{~g}$ for 20 minutes. $50 \mu \mathrm{g}$ of protein extract were separated by $10 \%$ SDS polyacrylamide gel electrophoresis, and transferred onto a $0.45 \mu \mathrm{m}$ polyvinylidene difluoride (PVDF) membrane (Whatman, Germany). The membrane was blocked for 1 hour at room temperature with blocking buffer $(\mathrm{pH}$ 7.6) containing $5 \%$ nonfat dry milk, then membranes were incubated with primary antibodies diluted in blocking buffer at $4^{\circ} \mathrm{C}$ overnight. The antibodies against MELK (Sigma-Aldrich, St. Louis, MO, USA), E-cadherin, N-cadherin, Akt, and Snail were all diluted at 1:1000.

\section{Flow cytometric analysis}

For cell cycle analysis, cells near 50\% confluence were synchronized in the $G_{0} / G_{1}$ phase by overnight incubation in serum-free medium. Cells were then incubated in the complete medium containing $25 \mathrm{nM}$ or $50 \mathrm{nM}$ OTSSP167. After 24 hours (BGC823) or 18 hours (SGC7901) of incubation, the cells were trypsinized, washed with PBS, and fixed with $70 \%$ ethanol for 16 hours at $-20^{\circ} \mathrm{C}$. The samples were washed with PBS and stained with PI/RNase Staining Buffer (BD Biosciences) for 15 minutes. Cell cycle analysis was performed by 
fluorescence flow cytometry on a FACScan machine (BD Biosciences). For apoptotic analysis, cells were stained using an Annexin V/PI double staining kit (DOJINDO, Japan) according to the manufacturer's protocol.

\section{In vivo mouse models of gastric cancer cell lines}

Animal studies were carried out in strict adherence with institutional guidelines. BGC823-shMELK cells and BGC823-shControl cells (approximately $1.5 \times 10^{6}$ cells in a $200 \mu \mathrm{l}$ volume per mouse) were injected into the right hind legs of 6-week-old BALB/c-nude mice (10 mice total, 5 mice per group). Tumor growth was monitored three times a week by measuring the width and length of the tumors with calipers. The tumor volume was calculated by the formula $\mathrm{V}=0.5 \times \mathrm{L} \times \mathrm{W}^{2}$.

BGC823 cells with or without MELK silencing $(0.5$ $\times 10^{6}$ cells in a $100 \mu \mathrm{l}$ volume per mouse) were injected intravenously via a 30 -gauge needle inserted into the tail vein of female BALB/C-nude mice (5-6 weeks old). Six weeks later, the mice were sacrificed, and the lungs were removed and fixed with Bouin's fixative. The presence of lung metastases was evaluated at autopsy.

\section{Establishment of GC-patient derived tumor xenograft mouse model bank}

Surgically removed GC tissues were obtained from Peking University Beijing Cancer Hospital with the approval of Institutional Review Boards, and an informed consent document was signed by patients, which covered the use of tumor material for research purposes. Tumors were delivered directly from the operating room to the laboratory in culture media (DMEM with 500 units $/ \mathrm{ml}$ penicillin and $500 \mathrm{ug} / \mathrm{ml}$ streptomycin). Pieces of non-necrotic tissue were chosen and minced into 1-3 $\mathrm{mm}^{3}$ pieces with ophthalmic scissors under sterile conditions. Minced tumor pieces and Matrigel (BD Biosciences) were mixed at a ratio of $1: 1$, then $100 \mathrm{ul}$ of tumor tissue homogenate was injected into the groin of each F1 generation mouse (4- to 6-week old female NOD/SCID (Beijing HFK Bioscience Co., Beijing, China)) subcutaneously using an 18 gauge needle. All procedures were completed within 1 hour after surgical specimens were harvested and placed on ice. The mice were maintained under pathogen-free conditions and a 12 hour light/dark cycle. When the tumors reached an approximate size of $1000 \mathrm{~mm}^{3}\left(1 / 2\right.$ length $\mathrm{x}$ width $\left.{ }^{2}\right)$, they were harvested, minced, and reinjected into $\mathrm{F} 2$ generation mice using the same method described for F1 mice.

A section of the tumor from each generation was fixed in $10 \%$ formalin and subsequently embedded in a paraffin block. All the tumor specimens, including the patient's primary tumor, were stained with hematoxylineosin (H \& E) and examined microscopically. Comparisons between primary tumor and TumorGraft samples were made by pathologists in order to exclude spontaneous lymphomas in the NOD/SCID mice.

\section{Evaluation of antitumor activity}

MELK-positive and -negative GC-PDX mouse models were randomly selected according to the results of IHC performed on the original GC and TumorGraft tissues. When tumor volume reached $100-200 \mathrm{~mm}^{3}$, the mice were randomly assigned to treatment and control groups and dosing was initiated. OTSSP167 was administered at $15 \mathrm{mg} / \mathrm{kg}$ intravenously to the third-generation mice once every two days for 2 weeks. The control group was treated with vehicle (PBS) in the same way. Tumor size was monitored every two days by caliper measurements. The weight of the mice was also measured as an indicator of treatment toleration. Tumor growth inhibition (TGI) was assessed in accordance with the formula $\{1-(\mathrm{T}-\mathrm{T} 0)$ $/(\mathrm{C}-\mathrm{C} 0)\} \times 100$, where $\mathrm{T}$ and $\mathrm{T}_{0}$ are the mean tumor volumes at the end of the drug administration and day 0 , respectively, for the treated group, and $\mathrm{C}-\mathrm{C}_{0}$ are those for the vehicle control group.

\section{Statistical analysis}

Chi-square tests were used to compare the differences in MELK protein expression. The overall survival (OS) curve was calculated with the Kaplan-Meier method and analyzed with the log-rank test. Relative risks (RRs) of death associated with MELK expression and other predictor variables were estimated by the univariate Cox proportional hazards model. Multivariate Cox models were also constructed to estimate the RR for MELK expression. All statistical analyses were carried out using SPSS statistical software (version 18.0; SPSS Inc., Chicago, IL, USA). A two-tailed $p$-value less than 0.05 was considered statistically significant.

\section{ACKNOWLEDGMENT}

We thank Dr. Bin Dong, Dr. Zhongwu Li and Dr. Min Zhao in Department of Pathology at the Peking University Cancer Hospital for excellent assistance in evaluating the IHC results.

\section{CONFLICTS OF INTEREST}

The authors declare no conflicts of interest.

\section{GRANT SPONSOR}

This work was supported by the Ministry of Science and Technology of the People's Republic of China (Grant No. 863 Program 2014AA020603, 2011BAZ03191 and 2014BAI09B02), the natural science Foundation of Beijing (No.7132051), the general program, Research Fund for the Doctoral program of Higher Education (No.2012001120135), 985 cooperation program between clinical and basic medicine of Peking University 
(Grant No. 2013-5-09) and the National Natural Science Foundation of China (No.81301874).

\section{REFERENCES}

1. Jemal A, Bray F, Center MM, Ferlay J, Ward E, Forman D. Global cancer statistics. CA Cancer J Clin. 2011; 61:69-90.

2. Wang J, Sun Y, Bertagnolli MM. Comparison of Gastric Cancer Survival Between Caucasian and Asian Patients Treated in the United States: Results from the Surveillance Epidemiology and End Results (SEER) Database. Ann Surg Oncol. 2015.

3. Kanat $\mathrm{O}, \mathrm{O}^{\prime} \mathrm{Neil} \mathrm{BH}$. Metastatic gastric cancer treatment: a little slow but worthy progress. Med Oncol. 2013; 30:464.

4. Gil M, Yang Y, Lee Y, Choi I, Ha H. Cloning and expression of a cDNA encoding a novel protein serine/threonine kinase predominantly expressed in hematopoietic cells. Gene. 1997; 195:295-301.

5. Heyer BS, Warsowe J, Solter D, Knowles BB, Ackerman SL. New member of the Snf1/AMPK kinase family, Melk, is expressed in the mouse egg and preimplantation embryo. Mol Reprod Dev. 1997; 47:148-156.

6. Blot J, Chartrain I, Roghi C, Philippe M, Tassan JP. Cell cycle regulation of $\mathrm{pEg} 3$, a new Xenopus protein kinase of the KIN1/PAR-1/MARK family. Dev Biol. 2002; 241:327-338

7. Heyer BS, Kochanowski H, Solter D. Expression of Melk, a new protein kinase, during early mouse development. Dev Dyn. 1999; 215:344-351.

8. Lin ML, Park JH, Nishidate T, Nakamura Y, Katagiri T. Involvement of maternal embryonic leucine zipper kinase (MELK) in mammary carcinogenesis through interaction with Bcl-G, a pro-apoptotic member of the Bcl-2 family. Breast Cancer Res. 2007; 9:R17.

9. Davezac N, Baldin V, Blot J, Ducommun B, Tassan JP. Human pEg3 kinase associates with and phosphorylates CDC25B phosphatase: a potential role for $\mathrm{pEg} 3$ in cell cycle regulation. Oncogene. 2002; 21:7630-7641.

10. Vulsteke V, Beullens M, Boudrez A, Keppens S, Van Eynde A, Rider MH, Stalmans W, Bollen M. Inhibition of spliceosome assembly by the cell cycle-regulated protein kinase MELK and involvement of splicing factor NIPP1. J Biol Chem. 2004; 279:8642-8647.

11. Nakano I, Paucar AA, Bajpai R, Dougherty JD, Zewail A, Kelly TK, Kim KJ, Ou J, Groszer M, Imura T, Freije WA, Nelson SF, Sofroniew MV, Wu H, Liu X, Terskikh AV, et al. Maternal embryonic leucine zipper kinase (MELK) regulates multipotent neural progenitor proliferation. J Cell Biol. 2005; 170:413-427.

12. Du T, Qu Y, Li J, Li H, Su L, Zhou Q, Yan M, Li C, Zhu Z, Liu B. Maternal embryonic leucine zipper kinase enhances gastric cancer progression via the FAK/Paxillin pathway. Mol Cancer. 2014; 13:100.
13. Jung H, Seong HA, Ha H. Murine protein serine/threonine kinase 38 activates apoptosis signal-regulating kinase 1 via Thr 838 phosphorylation. J Biol Chem. 2008; 283:34541-34553.

14. Nakano I, Masterman-Smith M, Saigusa K, Paucar AA, Horvath S, Shoemaker L, Watanabe M, Negro A, Bajpai R, Howes A, Lelievre V, Waschek JA, Lazareff JA, Freije WA, Liau LM, Gilbertson RJ, et al. Maternal embryonic leucine zipper kinase is a key regulator of the proliferation of malignant brain tumors, including brain tumor stem cells. J Neurosci Res. 2008; 86:48-60.

15. Alachkar $\mathrm{H}$, Mutonga $\mathrm{MB}$, Metzeler $\mathrm{KH}$, Fulton $\mathrm{N}$, Malnassy G, Herold T, Spiekermann K, Bohlander SK, Hiddemann W, Matsuo Y, Stock W, Nakamura Y. Preclinical efficacy of maternal embryonic leucine-zipper kinase (MELK) inhibition in acute myeloid leukemia. Oncotarget. 2014; 5:12371-12382. doi: 10.18632/ oncotarget.2642.

16. Choi $\mathrm{S}, \mathrm{Ku}$ JL. Resistance of colorectal cancer cells to radiation and 5-FU is associated with MELK expression. Biochem Biophys Res Commun. 2011; 412:207-213.

17. Kuner R, Falth M, Pressinotti NC, Brase JC, Puig SB, Metzger J, Gade S, Schafer G, Bartsch G, Steiner E, Klocker H, Sultmann H. The maternal embryonic leucine zipper kinase (MELK) is upregulated in high-grade prostate cancer. J Mol Med (Berl). 2013; 91:237-248.

18. Pickard MR, Green AR, Ellis IO, Caldas C, Hedge VL, Mourtada-Maarabouni M, Williams GT. Dysregulated expression of Fau and MELK is associated with poor prognosis in breast cancer. Breast Cancer Res. 2009; 11:R60.

19. Phillips HS, Kharbanda S, Chen R, Forrest WF, Soriano RH, Wu TD, Misra A, Nigro JM, Colman H, Soroceanu L, Williams PM, Modrusan Z, Feuerstein BG, Aldape K. Molecular subclasses of high-grade glioma predict prognosis, delineate a pattern of disease progression, and resemble stages in neurogenesis. Cancer Cell. 2006; 9:157-173.

20. Hebbard LW, Maurer J, Miller A, Lesperance J, Hassell J, Oshima RG, Terskikh AV. Maternal embryonic leucine zipper kinase is upregulated and required in mammary tumorinitiating cells in vivo. Cancer Res. 2010; 70:8863-8873.

21. Gu C, Banasavadi-Siddegowda YK, Joshi K, Nakamura Y, Kurt H, Gupta S, Nakano I. Tumor-specific activation of the C-JUN/MELK pathway regulates glioma stem cell growth in a p53-dependent manner. Stem Cells. 2013; 31:870-881.

22. Chung S, Suzuki H, Miyamoto T, Takamatsu N, Tatsuguchi A, Ueda K, Kijima K, Nakamura Y, Matsuo Y. Development of an orally-administrative MELKtargeting inhibitor that suppresses the growth of various types of human cancer. Oncotarget. 2012; 3:1629-1640. doi: 10.18632/oncotarget.790.

23. Sasaki T, Kuniyasu H, Luo Y, Kitayoshi M, Tanabe E, Kato D, Shinya S, Fujii K, Ohmori H, Yamashita Y. AKT activation and telomerase reverse transcriptase expression are 
concurrently associated with prognosis of gastric cancer. Pathobiology. 2014; 81:36-41.

24. Larue L, Bellacosa A. Epithelial-mesenchymal transition in development and cancer: role of phosphatidylinositol 3' kinase/AKT pathways. Oncogene. 2005; 24:7443-7454.

25. Marie SK, Okamoto OK, Uno M, Hasegawa AP, ObaShinjo SM, Cohen T, Camargo AA, Kosoy A, Carlotti CJ, Toledo S, Moreira-Filho CA, Zago MA, Simpson AJ, Caballero OL. Maternal embryonic leucine zipper kinase transcript abundance correlates with malignancy grade in human astrocytomas. Int J Cancer. 2008; 122:807-815.

26. Bertotti A, Migliardi G, Galimi F, Sassi F, Torti D, Isella C, Cora D, Di Nicolantonio F, Buscarino M, Petti C, Ribero D, Russolillo N, Muratore A, Massucco P, Pisacane A, Molinaro L, et al. A molecularly annotated platform of patient-derived xenografts ("xenopatients") identifies HER2 as an effective therapeutic target in cetuximab-resistant colorectal cancer. Cancer Discov. 2011; 1:508-523.

27. Weroha SJ, Becker MA, Enderica-Gonzalez S, Harrington SC, Oberg AL, Maurer MJ, Perkins SE, AlHilli M, Butler KA, McKinstry S, Fink S, Jenkins RB, Hou X, Kalli KR, Goodman KM, Sarkaria JN, et al. Tumorgrafts as in vivo surrogates for women with ovarian cancer. Clin Cancer Res. 2014; 20:1288-1297.

28. Jiang J, Wang DD, Yang M, Chen D, Pang L, Guo S, Cai J, Wery JP, Li L, Li HQ, Lin PP. Comprehensive characterization of chemotherapeutic efficacy on metastases in the established gastric neuroendocrine cancer patient derived xenograft model. Oncotarget. 2015. doi: 10.18632/ oncotarget.3712.

29. Gu Q, Zhang B, Sun H, Xu Q, Tan Y, Wang G, Luo Q, $\mathrm{Xu}$ W, Yang S, Li J, Fu J, Chen L, Yuan S, Liang G, Ji Q, Chen $\mathrm{SH}$, et al. Genomic characterization of a large panel of patient-derived hepatocellular carcinoma xenograft tumor models for preclinical development. Oncotarget. 2015. doi: 10.18632/oncotarget.3969.
30. Stebbing J, Paz K, Schwartz GK, Wexler LH, Maki R, Pollock RE, Morris R, Cohen R, Shankar A, Blackman G, Harding V, Vasquez D, Krell J, Zacharoulis S, Ciznadija D, Katz A, et al. Patient-derived xenografts for individualized care in advanced sarcoma. Cancer-Am Cancer Soc. 2014; 120:2006-2015.

31. Weroha SJ, Becker MA, Enderica-Gonzalez S, Harrington SC, Oberg AL, Maurer MJ, Perkins SE, AlHilli M, Butler KA, McKinstry S, Fink S, Jenkins RB, Hou X, Kalli KR, Goodman KM, Sarkaria JN, et al. Tumorgrafts as in vivo surrogates for women with ovarian cancer. Clin Cancer Res. 2014; 20:1288-1297.

32. Einarsdottir BO, Bagge RO, Bhadury J, Jespersen H, Mattsson J, Nilsson LM, Truve K, Lopez MD, Naredi P, Nilsson O, Stierner U, Ny L, Nilsson JA. Melanoma patient-derived xenografts accurately model the disease and develop fast enough to guide treatment decisions. Oncotarget. 2014; 5:9609-9618. doi: 10.18632/ oncotarget.2445.

33. Jager W, Xue H, Hayashi T, Janssen C, Awrey S, Wyatt AW, Anderson S, Moskalev I, Haegert A, Alshalalfa M, Erho N, Davicioni E, Fazli L, Li E, Collins C, Wang Y, et al. Patient-derived bladder cancer xenografts in the preclinical development of novel targeted therapies. Oncotarget. 2015; 6:21522-21532. doi: 10.18632/oncotarget.3974.

34. Wang Y, Lee YM, Baitsch L, Huang A, Xiang Y, Tong H, Lako A, Von T, Choi C, Lim E, Min J, Li L, Stegmeier F, Schlegel R, Eck MJ, Gray NS, et al. MELK is an oncogenic kinase essential for mitotic progression in basal-like breast cancer cells. Elife. 2014; 3:e1763.

35. Shao DF, Wang XH, Li ZY, Xing XF, Cheng XJ, Guo T, Du H, Hu Y, Dong B, Ding N, Li L, Li S, Li QD, Wen XZ, Zhang LH, Ji JF. High-level SAE2 promotes malignant phenotype and predicts outcome in gastric cancer. Am J Cancer Res. 2015; 5:140-154. 